\title{
ВMJ Global Health Improving the reporting of health research involving design: a proposed guideline
}

\author{
Alessandra N Bazzano (10 , ${ }^{1,2}$ Shirley D Yan, ${ }^{3}$ Jane Martin, ${ }^{4}$ Emma Mulhern, ${ }^{5}$ \\ Eleanor Brown, ${ }^{6}$ Anne LaFond, ${ }^{7}$ Ledia Andrawes, ${ }^{8,9}$ Tracy Pilar Johnson, ${ }^{10}$ \\ Shilpa Das ${ }^{11}$
}

To cite: Bazzano AN, Yan SD, Martin J, et al. Improving the reporting of health research involving design: a proposed guideline. BMJ Global Health 2020;5:e002248. doi:10.1136/ bmjgh-2019-002248

Received 19 December 2019 Revised 9 January 2020 Accepted 12 January 2020

Check for updates

C Author(s) (or their employer(s)) 2020. Re-use permitted under CC BY-NC. No commercial re-use. See rights and permissions. Published by BMJ.

For numbered affiliations see end of article.

Correspondence to Dr Alessandra N Bazzano; abazzano@tulane.edu

\section{DESIGN AND GLOBAL HEALTH}

The contribution of design to optimising global health interventions is increasingly recognised. ${ }^{1}$ The field of applied design is diverse and encompasses technical, creative and social skills and mindsets ${ }^{2}$; design may be carried out by expert designers or by 'diffuse' designers. ${ }^{3}$ Design for global health may involve design thinking, ${ }^{4}$ human-centred design ${ }^{5}$ service design and codesign. And the use of design for global health has especially been promoted in relation to the concept of social innovation. ${ }^{67}$

There is already a tradition in global health of using approaches such as transdisciplinarity, perspective taking or empathy, working with participants from across the spectrum of needs, iterating and creating products or services that will improve the lives of those affected. ${ }^{8}$ For example, some global health researchers actively seek to include the community of those who are experiencing health challenges into research in a participatory way.

Design seeks to accomplish a similar goal but with different perspectives, tools and strategies, and with a focus on innovation while recognising the potentially competing needs to reinvent versus innovate in the context of sustained existing knowledge and practice. There is a need to use design when and as appropriate to complement existing knowledge and practice, and to "balance a concern for understanding current or past practices with a concern for envisioning alternative or future practices, ${ }^{5}$

\section{THE NEED FOR GUIDELINES FOR REPORTING RESEARCH INVOLVING DESIGN}

In a previous scoping review of peer-reviewed journal articles on human-centred design and public health, ${ }^{9}$ we found that few articles included detailed methods and results, information on design expertise within teams,

\section{Summary box}

Design is being used more frequently in global health practice but is not reported on sufficiently for transparency, evaluability and wider dissemination.

- Reporting guidelines are useful in improving the quality and quantity of dissemination of work in peer-reviewed literature for global health.

- Building on available literature and current practice in design for global health, we present a reporting guideline that can be used by scholars and practitioners applying design in their work, and invite input on this work.

We present draft guidance which we recommend for reporting on design for global health in order to improve the evidence base for design in global health.

reflexivity/positionality or socioinstitutional dynamics. Importantly, much of the literature neglected to describe stakeholder engagement processes related to the use of design, which is a key feature of both global health and personcentred methods.

Existing guidelines are available for related disciplines such as qualitative health research and public involvement in health research. ${ }^{10}$ While these guidelines serve an important function, they are not sufficiently specific to the field of design for health, which is unique in several ways. Design for health necessitates including participants (and others who will use the design outcomes) explicitly in the research process, iterates on proposed solutions quickly and directly with participants, and makes the results more immediately actionable than is typical in theoretically driven social and behavioural, or qualitative, research.

Findings of research on health programming and implementation that involves design are beginning to appear in peer-reviewed health and medical journals, in addition to being found more typically in 'grey literature' 
not indexed by a commercial publisher, including public or private reports, working papers, government documents, white papers and evaluations. Clearer guidance for authors, journal editors, community members and peer reviewers will influence publication and the potential for stakeholders from diverse communities and disciplines to locate design-based health research. ${ }^{11}$ As the global health community increasingly seeks ways of scaling up beneficial interventions, clear and transparent reporting of approaches to achieve impact is warranted. ${ }^{12}$

Reporting guidelines add value and allow programme reports and research articles to be useful for a wider audience. ${ }^{13} 14$ Incomplete reporting makes research inaccessible, introduces bias and does not provide full transparency. ${ }^{15}$ Reporting guidelines for health research involving design may help investigation and programmatic activities to be shared and used more frequently and effectively.

Based on this analysis, and discussion among communities of practice in design for health, ${ }^{16}$ we have identified a set of items that are important for reporting on research that uses design. Inclusion of these items will make research that has applied design more transparent, so that global health practitioners can more easily understand what has been done, by whom, with whom and to what effect. Providing better information on design-based projects will also support global health stakeholders to determine if design could be usefully applied to their own work.

\section{PROPOSED GUIDELINES FOR REPORTING RESEARCH INVOLVING DESIGN}

In tables 1 and 2, we present a proposed draft set of guidelines for reporting on research that has incorporated design. This work represents the collaborative effort of a group of global health researchers, designers, funders and evaluators. We developed the guidelines drawing from processes described to develop other reporting guidelines such as the Consolidated Criteria for Reporting Qualitative Research ${ }^{17}$ and Standards for Quality Improvement Reporting Excellence ${ }^{18}$ guidelines.

In developing the guidelines, we consulted existing literature on guideline development processes, ${ }^{19}$ along with information drawn from the emerging field of design for health, to independently develop reporting checklists which we then collated and deduplicated, discussing any disagreement during group discussions. Finally, we jointly compiled the content presented in tables 1 and 2 . The guideline development process was recorded using the Enhancing the Quality and Transparency of Health Research network guidance, where registration can be located. ${ }^{20}$

The first table provides an outline and high-level overview of reporting elements that would support readers to understand the basic elements of the research, including the background or why the research has been done, the approach or how the research was done (by whom, with whom and in what way), the results of the research (and what design decisions or decision points led to the results, as well as impacts, if any, were noted) and, finally, a discussion and conclusion of how design informed the study, along with the way forward.

Table 2 provides more detail on what elements should be reported for those sections to be fully transparent and comprehensive. For example, including unique and key elements such as how the design challenge was framed (in the Background section) and what specific strategies or tools were used in the different design research phases of, for example, discovery or insight gathering versus testing or prototyping (in the Approach section).

The guidelines are intended to support teams involved in codesign of health research to disseminate their work in a systematic and transparent way for improved understanding across disciplines, to support researchers and practitioners with planning and reporting design-based

\section{Table 1 Recommended elements for reporting of global health research that has used design}

\begin{tabular}{|c|c|c|}
\hline Item & Paper section & Topic/descriptor \\
\hline 1 & Title and abstract & $\begin{array}{l}\text { Title should indicate that the study included a design approach. Abstract summarises the salient } \\
\text { components, including background, statement of problem, approach/methods, findings, results } \\
\text { and conclusion. }\end{array}$ \\
\hline 2 & Introduction/background & $\begin{array}{l}\text { Overview of the background to the topic, what has been done in the area already and rationale for } \\
\text { using design. Description of the initial research question or health problem that the design-based } \\
\text { work aimed to address. }\end{array}$ \\
\hline 4 & $\begin{array}{l}\text { Results/findings from } \\
\text { design research and } \\
\text { activities }\end{array}$ & $\begin{array}{l}\text { Summary of findings from design activities. Explanation of what was finally designed and what } \\
\text { the associated decision-making points were, and (if available) impact. Report on any secondary or } \\
\text { ancillary results. }\end{array}$ \\
\hline 5 & Discussion & $\begin{array}{l}\text { Reflection on the incorporation of design to this research topic, including but not limited to } \\
\text { strengths, limitations and contribution. }\end{array}$ \\
\hline
\end{tabular}


Table 2 Detailed reporting elements for reporting of global health research that has used design

\begin{tabular}{|c|c|c|c|}
\hline Item & Paper section & Succinct description & Detailed description \\
\hline 1. & Title & $\begin{array}{l}\text { Title should indicate that the study } \\
\text { included a design approach. }\end{array}$ & $\begin{array}{l}\text { Explicit mention of design in the title, what was designed, } \\
\text { what process was used, intended outcomes or potential } \\
\text { contribution. }\end{array}$ \\
\hline
\end{tabular}

\subsection{Abstract}

2. Introduction/backgroun
$2.1 \quad$ Available knowledge

Abstract summarises the salient components, including background, statement of the problem, approach/ methods, findings, results and conclusion.

\section{Overview of the background to the} topic, what has been done in the area already and rationale for using the design.

Statement of the health problem/design brief applied, noting whether qualitative or mixed method research (or other) was included.

Abstract should contain relevant information on the health issue, design practice, methods, results and conclusions.

Providing relevant references to the scope of the health issue, any previous work in this area or other ways of addressing the health topic; introduction of the design rationale.

Summary of what is known about the Literature review of past studies, knowledge and projects topic and any gaps relevant to the problem. Statement of what is known about the problem and what has been done to address it in the past, state of the art.

$\begin{array}{ll}2.2 & \begin{array}{l}\text { Rationale for design } \\ \text { approach }\end{array} \\ 2.3 & \begin{array}{l}\text { Description of design } \\ \text { challenge for health }\end{array}\end{array}$

Explanation of design as appropriate to address the topic.

Description of the main research question or health problem that the design-based work aimed to address.

\begin{tabular}{lll} 
2.4 & Research aims & $\begin{array}{l}\text { Overall aims and objectives of the } \\
\text { project. }\end{array}$ \\
\hline 3. & Methods/approach & $\begin{array}{l}\text { Description of approach used for the } \\
\text { research. }\end{array}$ \\
\hline 3.1 & Theory & $\begin{array}{l}\text { Underlying theories that informed } \\
\text { this work (if any). }\end{array}$ \\
3.2 & Process and timeline & $\begin{array}{l}\text { Processes or steps and timeline for } \\
\text { the research. }\end{array}$
\end{tabular}

3.3 Research team
characteristics and
reflexivity

Individuals involved in the research team and characteristics of these. Ways that reflextivity was addressed. reflexivity . 
Table 2 Continued

\begin{tabular}{llll}
\hline Item & Paper section & Succinct description & Detailed description \\
\hline 3.6 & Ethical considerations & Ethical precautions taken to protect & Ethics and information related to human subjects'
\end{tabular}

3.6 Ethical considerations Ethical precautions taken to protect participants, communities, and personal information.

protection for social-behavioural research; documentation of ethics approval (if any) by a review board and participant consent, or explanation for lack thereof; addressing privacy, confidentiality and data security and internationally recognised concepts and guidelines (eg, Declaration of Helsinki and Belmont Report).

\begin{tabular}{|c|c|c|}
\hline 3.7 & Language & $\begin{array}{l}\text { Description of any language } \\
\text { considerations. }\end{array}$ \\
\hline 3.8 & $\begin{array}{l}\text { Techniques to understand } \\
\text { (data collection tools and } \\
\text { instruments) }\end{array}$ & $\begin{array}{l}\text { Techniques or tools used during the } \\
\text { research process. }\end{array}$ \\
\hline
\end{tabular}

Language in which the project was conducted; if in translation, credentials of translators; checking for accuracy of materials or workshop translation; familiarity of designers and participants with language and cultural nuances. instruments)

Description of the types of the techniques or tools employed, rationale for method, type of data collected and any changes to methods during data collection. Description of who used research tools and with whom; should be stated separately for phases of discovery or insight gathering and testing or prototyping; what was done with this information and for what purpose it was done; any references to precedents for use.

$\begin{array}{ll}\text { 3.9 Documentation } & \text { Documentation of work undertaken } \\ \text { in research. }\end{array}$

Statement of how documentation was carried out (eg, notes, videos, and photos), by whom, what specifically was documented (eg, interviews, affinity exercises, and observations) and role of participants in documentation. Types of data collected (eg, potentially listing and numbering of interviews, photos, videos, notes, insight statements, prototypes and pile/card sorts).

\subsection{Techniques to synthesise Description of techniques used to} synthesise insights, iterate, and analyse data.

Explanation of process for team synthesis, analysis of collected information from the design work (eg, brainstorming and journey maps); inclusion of any data analysis software or use of large data sets to validate insights; description of team members involved in this process.

\begin{tabular}{|c|c|c|}
\hline 3.11 & Validation approaches & $\begin{array}{l}\text { Process of checking that insights, } \\
\text { prototypes or other products were } \\
\text { validated. }\end{array}$ \\
\hline 4. & $\begin{array}{l}\text { Results/findings from } \\
\text { design research and } \\
\text { activities }\end{array}$ & $\begin{array}{l}\text { Summary of findings from design } \\
\text { activities, resulting insights, what } \\
\text { was designed, what resulted from } \\
\text { the work and (if available) impact of } \\
\text { activities; report on any secondary or } \\
\text { ancillary results. }\end{array}$ \\
\hline
\end{tabular}

Description of additional steps used to verify, validate, triangulate or test the themes emerging (eg, comparing to existing literature, expert review and feedback from participants); summary of process of reflection for researchers to understand their own role in the development of the final products and steps taken to enhance validity of the solution (other than direct testing with a small number of users).

Description of what was created as a result of the work: intervention, solution, policy, technology, behaviour change, service or other result; inclusion of salient features of the solution; noting how these addressed underlying health topic and what happened after design (eg, intervention or product status); documentation of ownership of what was created in the process; description of research prototypes.

\begin{tabular}{|c|c|c|c|}
\hline 4.1 & Design research phase & $\begin{array}{l}\text { Summary of major insights or } \\
\text { reflection from design activities. }\end{array}$ & $\begin{array}{l}\text { Presentation of design research: } \\
\text { Problem framing. } \\
\text { Design insights. } \\
\text { Development and refinement of insights (diverge/ } \\
\text { converge). } \\
\text { Description of prototyping and use of measurement/ } \\
\text { assessment and iterative refinement. } \\
\text { Deliverables (eg, service blueprints, maps, prototypes, } \\
\text { storyboard). }\end{array}$ \\
\hline
\end{tabular}


Table 2 Continued

\begin{tabular}{llll}
\hline Item & Paper section & Succinct description & Detailed description \\
\hline 4.3 & $\begin{array}{l}\text { Evidence of change or } \\
\text { impact }\end{array}$ & $\begin{array}{l}\text { Summary of any evidence of change } \\
\text { or impact to health or other facets of } \\
\text { the situation. }\end{array}$ & $\begin{array}{l}\text { Description of change or impact if any was noted, including } \\
\text { any negative or null results; if evaluation has been done, } \\
\text { what, if any, direct health benefits or other benefits, } \\
\text { including social transformation, were identified and } \\
\text { description by whom these were identified. }\end{array}$
\end{tabular}

5. Discussion

Reflection on design as an approach Brief reiteration of findings or results; description of any to the health topic and the strengths limitations, strengths or challenges faced during research; and limitations of the work. description of how the results fit with other solutions for this health topic and how conclusions were arrived at in similar or different ways.

$\begin{array}{ll}\text { 5.1 Design } & \begin{array}{l}\text { Reflection of the application of } \\ \text { design to this research topic. }\end{array} \\ \text { 6. Conclusion } & \begin{array}{l}\text { Implications of this work for the } \\ \text { larger field and next steps. }\end{array}\end{array}$

Discussion of the transferability and specific contribution of design; description of how the solution developed is different from previous ones and fills any gap in knowledge; possible interpretation or development of a new model or methodology.

Explanation of the next key research or action to address the health topic and broader fields, noting implications for other practitioners or relevance to other contexts, commenting on the future of design for this domain.

\begin{tabular}{|c|c|c|c|}
\hline 7. & Other & $\begin{array}{l}\text { Acknowledgements of support, } \\
\text { assistance, funding, statement on } \\
\text { conflict of interest and authors' } \\
\text { contributorship. }\end{array}$ & $\begin{array}{l}\text { Description of any material interest of those involved in } \\
\text { the research, including paid consulting. } \\
\text { Statement of funding (if provided and by whom). } \\
\text { Description of the research team's ongoing commitment } \\
\text { to addressing any issues raised by participants during } \\
\text { the research. } \\
\text { Contributorship } \\
\text { Description statement regarding roles each author had in } \\
\text { research and reporting. }\end{array}$ \\
\hline 7.1 & Glossary & Definition of key terms & $\begin{array}{l}\text { Any terminology, especially design terminology, which may } \\
\text { not be understood in the lay, health, or biomedical context } \\
\text { and vice versa. }\end{array}$ \\
\hline
\end{tabular}

research, and crucially, to improve the potential of the public to review and interpret it. With more frequent reporting and documenting of transparent, evaluable design-based practices, we can go farther to promote global health programme responsiveness, effectiveness and equity.

\section{AN INVITATION FOR INPUT}

The guidelines presented here serve as a prototype for the development of comprehensive reporting guidance on design for global health. We provide these guidelines for public comment in the hope that gathering input from the global health community will improve the reporting and evaluating of health research that has incorporated design. We invite input from all stakeholders who create and use health research involving design on the guidelines presented through an open survey mechanism (see REDR Survey).

The current guideline will be modified in response to feedback, and a final prototype will be tested through a two-round, electronic Delphi process. With this feedback in the guideline development process, stakeholders will be able to contribute to making research more accessible and more transparent. It is anticipated that the publication of this commentary will elicit momentum to build the evidence base for the use of design in global health.

Ultimately, stronger reporting guidelines for health research involving design will ensure that research and programmatic activities can be shared and used more. Interdisciplinarity drives innovation in global health research, necessitating that the products of novel research partnerships and processes are disseminated widely. In order to enable diffusion of potentially catalytic approaches such as design, reporting must appear more readily in literature reviewed by stakeholders in global health.

We hope that in providing guidance to increase and improve reporting on design for health, this may be accomplished while respecting varied disciplinary traditions and meeting the needs of a wider community of global health stakeholders.

\section{Author affiliations}

${ }^{1}$ Department of Global Community Health and Behavioral Sciences, School of Public Health and Tropical Medicine, Tulane University, New Orleans, Louisiana, USA

${ }^{2}$ Taylor Center for Social Innovation and Design Thinking, Tulane University, New Orleans, LA, USA 
${ }^{3}$ Johns Hopkins Bloomberg School of Public Health, Johns Hopkins University, Baltimore, Maryland, USA

${ }^{4}$ Creative Social Change, London, UK

${ }^{5}$ Sightsavers, Haywards Heath, UK

${ }^{6}$ Itad Ltd, Brighton, UK

${ }^{7}$ John Snow, Inc, Arlington, Virginia, USA

${ }^{8}$ University College London, London, UK

${ }^{9}$ Sonder Collective, London, UK

${ }^{10}$ Bill \& Melinda Gates Foundation, Seattle, Washington, USA

${ }^{11}$ National Institute of Design, Ahmedabad, Gujarat, India

Twitter Alessandra N Bazzano @alessandrabazz and Jane Martin @c_ socialchange

Contributors ANB, SDY and JM: conceived of the presented idea. ANB, SDY, JM, EM, EB, ALF, LA, TPJ and SD: drafted the manuscript. ANB: supervised the project. All authors discussed the results and contributed to the final version of the manuscript.

Funding The authors have not declared a specific grant for this research from any funding agency in the public, commercial or not-for-profit sectors.

Competing interests None declared.

Patient consent for publication Not required.

Provenance and peer review Not commissioned; internally peer reviewed.

Data availability statement № data are available.

Open access This is an open access article distributed in accordance with the Creative Commons Attribution Non Commercial (CC BY-NC 4.0) license, which permits others to distribute, remix, adapt, build upon this work non-commercially, and license their derivative works on different terms, provided the original work is properly cited, appropriate credit is given, any changes made indicated, and the use is non-commercial. See: http://creativecommons.org/licenses/by-nc/4.0/.

ORCID iD

Alessandra N Bazzano http://orcid.org/0000-0002-8299-2626

\section{REFERENCES}

1 Fabricant R. When will design get serious about impact? (SSIR). Stanford Social Innovation Review, 2014

2 Design for Health. Bill \& Melinda Gates Foundation and USAID. Available: https://www.designforhealth.org/
3 Manzini E. Design, when everybody designs: an introduction to design for social innovation. Cambridge, Massachusetts: The MIT Press, 2015.

4 Brown T, Thinking D. Design thinking. Harv Bus Rev 2008;86:84-92.

5 Steen M. Tensions in human-centred design. CoDesign 2011;7:45-60.

6 Lister C, Payne H, Hanson CL, et al. The public health innovation model: merging private sector processes with public health strengths. Front Public Health 2017:5:192.

7 Bloom G, Wilkinson A, Bhuiya A. Health system innovations: adapting to rapid change. Global Health 2018;14:29.

8 Chen E, Leos C, Kowitt SD, et al. Enhancing community-based participatory research through Human-Centered design strategies. Health Promot Pract 2020;21:37-48.

9 Bazzano AN, Martin J, Hicks E, et al. Human-centred design in global health: a scoping review of applications and contexts. PLoS One 2017:12:e0186744.

10 O'Brien BC, Harris IB, Beckman TJ, et al. Standards for reporting qualitative research: a synthesis of recommendations. Acad Med 2014:89:1245-51.

11 Altman M, H T, B J. Design thinking in health care. Preventing Chronic Disease 2019;15:18012.

12 Milat AJ, Bauman A, Redman S. Narrative review of models and success factors for scaling up public health interventions. Implement Sci 2015;10:113.

13 Glasziou P. The role of open access in reducing waste in medical research. PLoS Med 2014:11:e1001651.

14 Glasziou P, Chalmers I. Research waste is still a scandal-an essay by Paul Glasziou and lain Chalmers. BMJ 2018;351:k4645.

15 Chan A-W, Song F, Vickers A, et al. Increasing value and reducing waste: addressing inaccessible research. Lancet 2014;383:257-66.

16 USAID. Innovation and impact Newsletter. United States Agency for International Development, 2019.

17 Tong A, Sainsbury P, Craig J. Consolidated criteria for reporting qualitative research (COREQ): a 32-item checklist for interviews and focus groups. Int J Qual Health Care 2007;19:349-57.

18 Ogrinc G, Davies L, Goodman D, et al. SQUIRE 2.0 (Standards for QUality Improvement Reporting Excellence): revised publication guidelines from a detailed consensus process: Table 1. BMJ Qual Saf 2016;25:986-92.

19 EQUATOR. How to develop a reporting guideline, 2018. Available: http://www.equator-network.org/toolkits/developing-a-reportingguideline/

20 EQUATOR. Reporting guidelines under development, 2018. Available: http://www.equator-network.org/library/reportingguidelines-under-development/reporting-guidelines-underdevelopment-for-other-study-designs/\#92 